\title{
Association Study on Urban Form and Urban Resources Efficiency Based on GIS and DEA: A Case Study of Shanghai
}

\author{
Wenping Fan $^{1}$, Yan $\mathrm{Liu}^{2}$, Yishao $\mathrm{Shi}^{3}$ \\ ${ }^{1}$ College of Civil Engineering, Shandong Jianzhu University, Jinan 250101, P. R. China \\ ${ }^{2}$ School of Geography, Planning and Environmental Management, the University of Queensland, Brisbane Qld 4072, \\ Australia \\ ${ }^{3}$ College of Surveying and Geo-Informatics, Tongji University, Shanghai 200092, P. R. China
}

\begin{abstract}
Rapid urbanisation has resulted in the change of urban forms as well as increased consumption of various urban resources. This paper reports an empirical study of China's Shanghai municipality to investigate the relationship between urban form and the efficiency usage of urban resources. Based on a series of Landsat imagery over the period from 1982 to 2008, the changing characteristics of the urban spatial forms in Shanghai were measured in GIS. Urban resources efficiency was measured through Data Envelopment Analysis (DEA) approach. By correlating the urban form and resource efficiency indicators through a regression analysis, the results show that the changes of urban resource efficiency are closely related to changes of urban forms. In general, the instability and complexity of the external form of the city reduces the urban resources efficiency. Moreover, high population density conduces to lower urban resources efficiency. In addition, the road network density and the spatial accessibility through the road network impact significantly the improvement of urban resources efficiency; besides, the compactness of urban external form does not have much influence on urban resources efficiency according to this study.
\end{abstract}

Keywords-geographic information system (GIS); data envelopment analysis (DEA); urban form; urban resources efficiency; shanghai.

\section{INTRODUCTION}

Sustainable development refers to the coordinated development of economy, society, population, resources and the environment. Resources are the fundamental factors for economic maintenance and growth; while, resources are limited, some of them are even non-renewable. Hence enhancing the efficient utilization of resources and avoiding waste are critical to realize sustainable urban development. Urban resources efficiency refers to the profit-gaining ability by inputting urban resources in urban activities. Essentially, urban resources efficiency is not only a measurement of rationality and efficiency of urban resources utilization, but also a critical criterion for assessing urban sustainable development ability. Urban resources efficiency is affected by many factors, among which urban form and structure is one of the important ones. Changes of urban form reflect comprehensively the change of spatial layout and structure during the process of urban development, as well as the social and economic development of cities; which can influence various aspects like urban traffic, environment, resources utilization, production and living and even the sustainable development, and also influence urban efficiency inevitably.

In order to research how urban resources efficiency changes with urban form evolves, and explore further the relationship between urban form and urban resources efficiency, this paper investigates urban resources efficiency in the view of urban form, and discusses the influence characteristic and mechanism of urban form evolution on the efficiency of urban resources utilization, taking the metropolitan area of Shanghai as a case.

\section{STUDY AREA AND DATA}

Shanghai is located in the geographical center of Asia-Pacific urban agglomeration as well as at the estuary of Yangtze River. The total area of Shanghai is $6340.5 \mathrm{~km}^{2}$; and the population by the end of 2010 had reached 23.02 which make Shanghai as one of the most populous cities in the world. Thanks to the advantages in policy, geography and history, Shanghai has entered a stage of rapid urbanization with the economic recovery and growth since the 1980 s.

Data was obtained through remote sensing images that consist of 1:30 Thematic Mapper (TM) and Enhanced Thematic Mapper (ETM) remote sensing images of Shanghai in the year 1982, 1989, 1992, 1999, 2001, 2003, 2005 and 2008. The image fusion has been conducted in ERDAS Imagine 9.2 to facilitate the extraction of the urban outlines in Geographic Information System (GIS).

Given the influencing lag of urban form indices, the data for calculating resources efficiency were delayed for one year after the corresponding data of urban form. All the data used in analysing urban resources efficiency are from the Shanghai statistical yearbook (1984 2001). Urban resources include land resources, labour resources, energy resources and water consumptions.

\section{Methodology}

\section{A. Measures of urban form}

Fractal dimension and compactness ratio are commonly used in the research of urban form as they are independent 
of each other and have strong complementarities as well as effect of mutual authentication $[1,2]$.

\section{Fractal Dimension}

Fractal dimension of urban spatial shape represents the complexity of urban expansion and to a certain extent the human influence on urban form. It also reflects changes on spatial layout and structure in urban development process [3]. In this paper, boundary dimension was chosen to research the fractal dimension of Shanghai urban spatial form.

$$
D=2 \lg (P / 4) / \lg (A)
$$

where ' $D$ ' represents the ability of graphs (or systems) on filling space and the irregular degree of graphic boundary; ' $A$ ' and ' $P$ ' refer separately to the area and the perimeter of spatial shape.

\section{Compactness Ratio}

compact degree of urban spatial form is one of the primary indices to measure urban form. A compact city is generally considered as resource-saving and environment-friendly; it also comply with long-term sustainable pattern of urban development [4,5] According to the study of Batty (2001)[6], the compactness of urban form can be measured by:

$$
B C I=2 \sqrt{\pi A} / P
$$

where ' $\mathrm{BCI}$ ' is the compactness ratio of urban land, ' $\mathrm{A}$ ' represents the area of urban built-up area, ' $\mathrm{P}$ ' is the perimeter of the urban outline.

\section{Intelligibility of urban space}

Spatial intelligibility is a crucial index in space syntax theory which was put forward by Hillier in 1970s [7]; it can represent comprehensively the accessibility of urban space and the relationship between local and global space. The formula is:

$$
R^{2}=\frac{\left[\sum\left(I_{(3)}-\bar{I}_{(3)}\right)\left(I_{(n)}-\bar{I}_{(n))}\right]^{2}\right.}{\sum\left(I_{(3)}-\bar{I}_{(3)}\right)^{2} \sum\left(I_{(n)}-\bar{I}_{(n)}\right)^{2}}
$$

where $I_{(3)}$ is the three-step integration of spatial axial lines, $\bar{I}_{(3)}$ is the mean value of three-step integration, $I_{(\mathrm{n})}$ is the global integration of arbitrary axial lines in space, $\bar{I}_{(n)}$ is the mean value of global integration [8]. City possesses spatiality and temporality, methods above will merely be the abstract mathematical analysis without support of GIS. Therefore, quantitative research on geometry features as well as development changes and complexity of urban spatial form have been conducted in this paper, combined with spatial analysis technology, fractal method and topological analysis of GIS for urban form [9].

\section{B. Measures of efficiency}

Data Envelopment Analysis (DEA) is a non-parametric method proposed by Charnes et al [10] to evaluate the relative efficiency between objects of the same type by mathematical programming. Assume that an evaluation system has ' $n$ ' evaluated objects (namely the DMU), and the evaluation indices system is composed of ' $\mathrm{m}$ ' input indices and ' $\mathrm{s}$ ' output indices, among which, input and output vectors of the $j$-th DMU are $X_{j}=\left(x_{1 j}, x_{2 j}, \ldots x_{m j}\right)^{T}>0$ 和 $Y_{j}=\left(y_{1 j}, y_{2 j}, \ldots y_{s j}\right)^{T}>0, j=1,2, \ldots n$. For a selected $D_{M U}$, the
DEA model of constant returns to scale (CRS) that can judge its efficiency with non-Archimedean infinitesimal ' $\varepsilon$ ' is as follows:

$$
\text { (D) } \mathrm{C}^{2} \mathrm{R}\left\{\begin{array}{l}
\min \left[\theta-\varepsilon\left(\hat{e}^{T} S^{-}+e^{T} S^{+}\right)\right] \\
\text {s.t. } \sum_{j=1}^{n} X_{j} \lambda_{j}+S^{-}=\theta X_{0} \\
\sum_{j=1}^{n} Y_{j} \lambda_{j}-S^{+}=Y_{0} \\
\lambda_{j} \geq 0, j=1,2, \ldots, n, S^{-} \geq 0, S^{+} \geq 0
\end{array}\right.
$$

where: $\hat{e}=(1,1, \ldots, 1)^{\mathrm{T}} \in E_{m}, \quad e=(1,1, \ldots, 1)^{\mathrm{T}} \in E_{S} ; \mathrm{S}^{-}$ and $\mathrm{S}^{+}$are slack variables. ' $\theta$ ' $(0<\theta \leq 1)$ is the efficiency index of $\mathrm{DMU}_{0}$ (it refers to the effective use of input relative to output); ' $\lambda_{\mathrm{j}}$ ' is the weight variable; ' $\mathrm{S}$ ' ' and ' $\mathrm{S}^{+}$, are slack variables (' $\mathrm{S}$ ' ' represents input redundancy, ' $\mathrm{S}$ ', represents output insufficiency). The CRS model can be transformed into the DEA model of variable returns to scale (VRS) when introducing the constraint $\sum_{j=1}^{n} \lambda_{j}=1$, with which urban efficiency can be decomposed as the product of pure technical efficiency $\left(\theta_{\mathrm{b}}\right)$ and scale efficiency (SE).

In this paper, indices we used to evaluate efficiency are listed as follows (Table 1). CRS and VRS models introduced above were accepted to compute the resources efficiency of Shanghai over different years.

TABLE I. INDICES QUANTIFYING URBAN RESOURCE EFFICIENCY

\begin{tabular}{ll}
\hline Indices type & Name of the Indices \\
\hline & Built-up area (sq.km) \\
& Employees in the secondary and tertiary \\
& industry (10000 persons) \\
Input indices & Electricity consumption \\
& $(100$ million kwh) \\
& Sales volume of tap water \\
& $(100$ million cu.m) \\
\hline & GDP (100 million yuan) \\
Output indices & GDP of the secondary and tertiary industry (100 \\
& million yuan)
\end{tabular}

\section{RESULTS AND ANALYSIS}

\section{A. Transformation of urban form in Shanghai}

Based on TM and ETM remote sensing images of 8 time phases in Shanghai, the characteristics of urban spatial form was extracted by using Erdas Imagine 9.2 and ArcGIS 9.2. The outcome of the manually extraction in GIS is as follows (Fig.1), and the calculated urban form indices are listed in table 2 . 


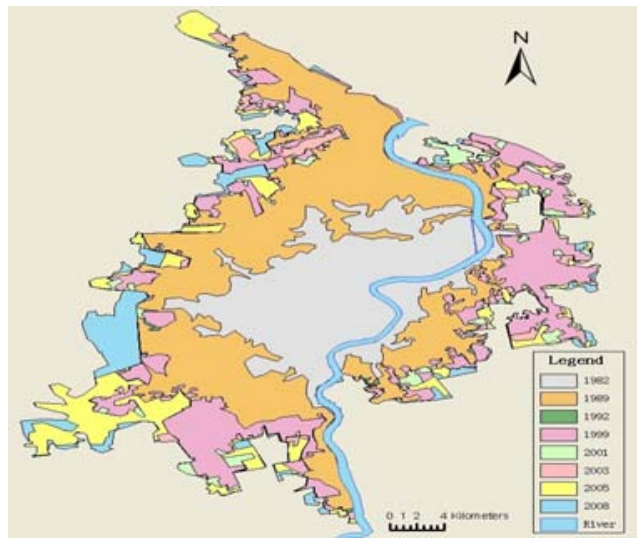

Figure.1. Changes of urban form in Shanghai (1982-2008)

TABLE II. URBAN FORM INDICES OF SHANGHAI

\begin{tabular}{ccccc}
\hline Year & FD & BCI & $\begin{array}{c}\text { PD } \\
\left(10000 \text { persons } / \mathrm{Km}^{2}\right)\end{array}$ & $\begin{array}{c}\mathrm{RNP} \\
\left(\mathrm{Km} / \mathrm{Km}^{2}\right)\end{array}$ \\
\hline 1982 & 1.40948 & 0.30004 & 11440.23 & 1.46 \\
\hline 1989 & 1.41302 & 0.24473 & 10758 & 2.02 \\
\hline 1992 & 1.40308 & 0.25217 & 10315 & 1.98 \\
\hline 1999 & 1.42565 & 0.22286 & 9754 & 6.41 \\
\hline 2001 & 1.39247 & 0.2468 & 9777 & 11.36 \\
\hline 2003 & 1.3837 & 0.2528 & 9807 & 12.87 \\
\hline 2005 & 1.35703 & 0.27066 & 9861 & 15.05 \\
\hline 2008 & 1.3347 & 0.28839 & 9881 & 19.51 \\
\hline
\end{tabular}

The intelligibility scatterplots of road network in Shanghai was obtained by the space syntax computation (see Fig.2), from which it is clear that, the correlation coefficient between global integration and local integration of road network is 0.742 in 1988 , which increased to 0.768 in 2001 and reached 0.796 in 2008. Figure 2 reveals that $t$ space of Shanghai was becoming more and more 'intelligent'.

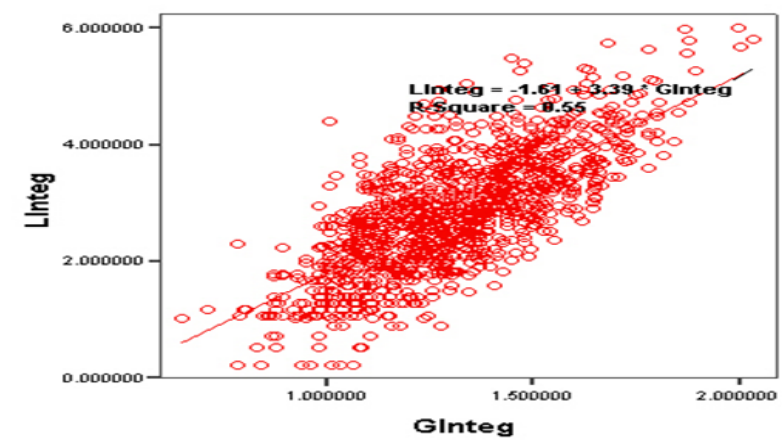

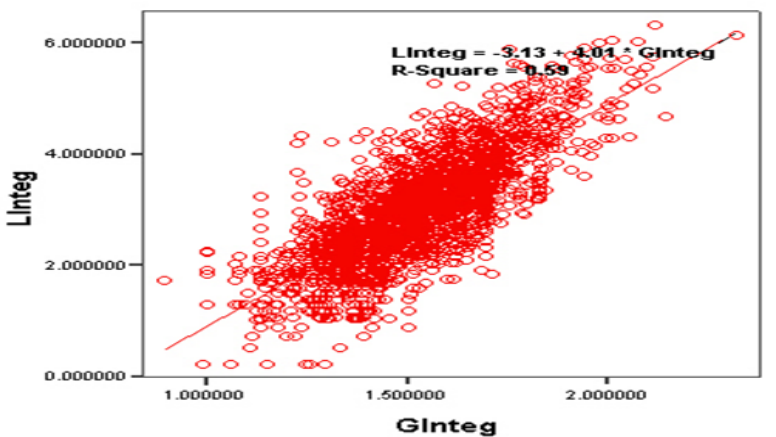

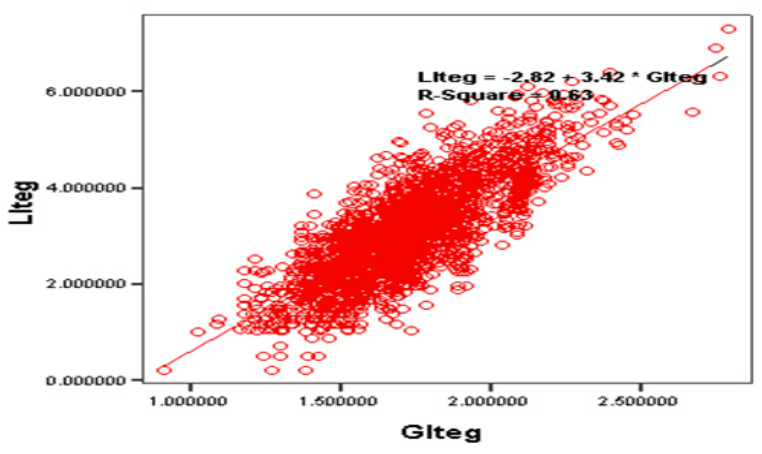

Figure.2. Scatterplot of Intelligibility

\section{B. Change in urban resources efficiencies}

In order to let the output indices comparable, GDP data have been smoothed by the GDP deflator and the output indices of all years have been conversed to the real GDP in which the GDP of year 1978 is 100 . Calculated result of urban resources efficiency of Shanghai from 1983 to 2009 by DEA is as follows (table3):

Where 'crste' refers to the urban resources comprehensive efficiency, 'vrste' is the urban resources pure technical efficiency and 'scale' is the urban resources scale efficiency. 
TABLE III. RESOURCES EFFICIENCY OF SHANGHAI (1983 2009)

\begin{tabular}{|c|c|c|c|c|c|c|c|c|c|}
\hline firm & crste & vrste & scale & irs/drs & firm & crste & vrste & scale & irs/drs \\
\hline 1983 & 0.519 & 1.000 & 0.519 & irs & 1997 & 0.707 & 0.890 & 0.795 & irs \\
\hline 1984 & 0.547 & 1.000 & 0.547 & irs & 1998 & 0.732 & 0.905 & 0.809 & irs \\
\hline 1985 & 0.563 & 1.000 & 0.563 & irs & 1999 & 0.778 & 0.940 & 0.828 & irs \\
\hline 1986 & 0.552 & 0.953 & 0.579 & irs & 2000 & 0.773 & 0.926 & 0.835 & irs \\
\hline 1987 & 0.560 & 0.919 & 0.690 & irs & 2001 & 0.811 & 1.000 & 0.811 & irs \\
\hline 1988 & 0.586 & 0.921 & 0.636 & irs & 2002 & 0.832 & 0.996 & 0.836 & irs \\
\hline 1989 & 0.588 & 0.914 & 0.644 & irs & 2003 & 0.856 & 1.000 & 0.856 & irs \\
\hline 1990 & 0.571 & 0.876 & 0.652 & irs & 2004 & 0.855 & 0.976 & 0.876 & irs \\
\hline 1991 & 0.497 & 0.866 & 0.573 & irs & 2005 & 0.854 & 0.970 & 0.881 & irs \\
\hline 1992 & 0.523 & 0.894 & 0.585 & irs & 2006 & 0.919 & 0.980 & 0.938 & irs \\
\hline 1993 & 0.557 & 0.843 & 0.660 & irs & 2007 & 1.000 & 1.000 & 1.000 & - \\
\hline 1994 & 0.585 & 0.840 & 0.697 & irs & 2008 & 0.954 & 0.969 & 0.985 & irs \\
\hline 1995 & 0.627 & 0.838 & 0.748 & irs & 2009 & 1.000 & 1.000 & 1.000 & - \\
\hline
\end{tabular}

C. Correlation between urban form and urban resource efficiency

calculation were charted in figure 3, and the correlation coefficient data were computed in table 3 :

Data of urban form and urban resources obtained from
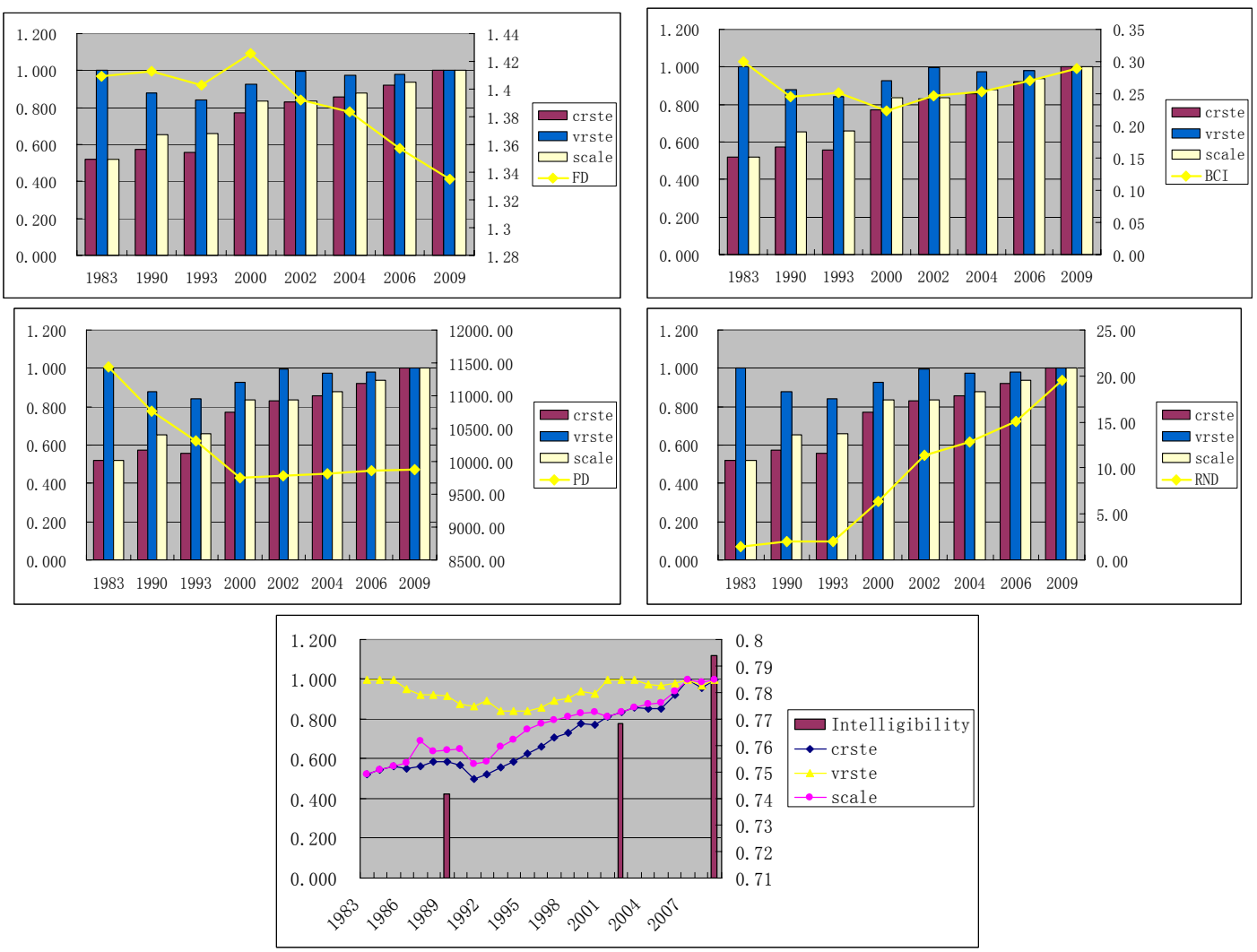

Figure 3. Relationship between urban form and urban efficiency 
TABLE IV. CORRELATION BETWEEN URBAN FORM AND URBAN RESOURCES EFFICIENCY

\begin{tabular}{|c|c|c|c|c|}
\hline & & crste & vrste & scale \\
\hline \multirow{3}{*}{ FD } & $\begin{array}{l}\text { Pearson } \\
\text { Correlation }\end{array}$ & $-.775^{*}$ & -.519 & $-.728 *$ \\
\hline & Sig. (2-tailed) & .024 & .188 & .040 \\
\hline & $\mathrm{N}$ & 8 & 8 & 8 \\
\hline \multirow{3}{*}{ BCI } & $\begin{array}{c}\text { Pearson } \\
\text { Correlation } \\
\end{array}$ & .038 & .539 & -.107 \\
\hline & Sig. (2-tailed) & .929 & .168 & .800 \\
\hline & $\mathrm{N}$ & 8 & 8 & 8 \\
\hline \multirow{3}{*}{ PD } & $\begin{array}{c}\text { Pearson } \\
\text { Correlation }\end{array}$ & $-.812 * *$ & -.140 & $-.885^{* *}$ \\
\hline & Sig. (2-tailed) & .003 & .599 & .000 \\
\hline & $\mathrm{N}$ & 8 & 8 & 8 \\
\hline \multirow{3}{*}{ RND } & $\begin{array}{c}\text { Pearson } \\
\text { Correlation } \\
\end{array}$ & $.978^{* *}$ & .637 & $.937 * *$ \\
\hline & Sig. (2-tailed) & .000 & .096 & .001 \\
\hline & $\mathrm{N}$ & 8 & 8 & 8 \\
\hline
\end{tabular}

$* *$ Correlation is significant at the 0.01 level (2-tailed)

Fractal dimension is negatively related to urban resources efficiency on the whole, namely, as fractal dimension is decreasing, urban form becomes more simple and regular, the urban form by now is beneficial to the efficient utilization of urban resources, especially for land resources and labour resources. As is shown in fiture2, the fractal dimension fluctuated greatly from 1983 to 2000, and achieved the maximum by 2000 , it suggest that the city at that time was intensively developed and the overall urban form was relatively fragmentized and discrete, theoretically the resources efficiency at this time should have been decreased, while the fact is on the contrary, it means that during this period of time the improvement of urban resources efficiency was mainly affected by other factors. After 2000, the fractal dimension reduced gradually, which represent that urban form tended to be stable, and it was the internal filling dominant, while various urban resources efficiency increased gradually, the complexity of urban external form has comparatively high impact on urban resources efficiency; data in table 4 can also prove the above analysis: fractal dimension has a moderately significant negative correlation with urban resources efficiency.

The compactness ratio of urban form in Shanghai from 1983 to 2009 has experienced two phases: From 1983 to 2000, with the implementation of reform and opening up, Shanghai city developed quickly, resulting in the fluctuating decrease of compactness of urban spac.; After 2000, with the old city's renovation and upgrade, the city development became stable, thus the urban form became more compact; in this time period, the compactness of urban form and the urban resources efficiency showed the same changing trend. Combining with data in table4, we can see that the correlation coefficient of compactness ratio and urban resources efficiency is only 0.038 , indicating that the compactness ratio of urban form is not directly related to the value of urban resources efficiency.
On the whole, urban PD and urban resources efficiency have opposite changing trend, revealing PD has a negative impact on urban resources efficiency; table 3 also shows a significant inverse correlation between the two (the correlation coefficient is -0.812). With the growth of PD, urban resources efficiency could decline in a certain extent. At the same time, it is clear that the resources scale efficiency is also inversely correlated with PD, which shows that the larger the PD, the less returns will be gained by enlarging the resources scale. As to the urban resources technical efficiency, its change relates little with PD.

From figure 3 and table 4 , it is clear that there exists a highly significant positive correlation between road network density and urban efficiency. The higher of level of urban road infrastructure, the higher of urban resources efficiency; which indicates that the allocation of urban resources is more convenient and optimized, in addition the resources circulation is easier, hence it would be beneficial to increase the utilization efficiency of urban resources, and meanwhile the input scale of urban resources will have more room for improvement. As for the impact on pure technical efficiency of urban resources, there has no obvious rules; they are only moderately related (the correlation coefficient is 0.637 ), showing that the level of urban road infrastructure does have some impact on urban resources technical efficiency, but that is not too much.

As we can see in figure 3 , the intelligibility of road configuration in Shanghai rose from 0.742 in 1988 to 0.768 in 2001 and then achieved 0.794 in 2008 . Correspondingly urban resources efficiency was increasing steadily; thereby we can see basically that there exists a positive correlation between them. This is due to the fact that intelligibility can reflect the internal accessibility level of a city to some extent, the improvement of it is helpful to the resources allocation and fluxion naturally, and consequently the urban resources efficiency could be increased.

\section{Regression Analysis of urban form and urban resources efficiency}

Before conducting regression analysis, the principal component analysis is considered to execute first, and then the urban form indices will be replaced by several principal components which are not related to each other. By the computation of SPSS13, two principal components $\left(\mathrm{F}_{1}, \mathrm{~F}_{2},\right)$ were extracted, and the variance of all urban form indices could be explained for $97.942 \%$ by these two principal components.

Relational expressions as follows can be written by the component score coefficient matrix, namely, ' $\mathrm{F}_{1}$ ' and ' $\mathrm{F}_{2}$ ' are the linear combination of urban form indices.

$$
\begin{array}{r}
F_{1}=0.392 \mathrm{FD}-0.116 \mathrm{BCI}+0.285 \mathrm{PD}-0.413 \mathrm{RND} \\
\mathrm{F}_{2}=-0.203 \mathrm{FD}+0.622 \mathrm{BCI}+0.472 \text { PD }-0.042 \text { RND }
\end{array}
$$

Finally, the multivariate linear regression analysis of urban form principal components $\left(\mathrm{F}_{1}, \mathrm{~F}_{2}\right)$ and urban resources efficiency $\left(\mathrm{Y}_{\text {crste }}\right)$ was carried out (Table 5): 
TABLE V. RESULTS OF REGRESSION ANALYSIS

\begin{tabular}{|c|c|c|c|c|c|c|c|}
\hline & R Square & $\begin{array}{l}\text { Adjusted } \\
\text { R Square }\end{array}$ & $\begin{array}{l}\text { Unstandardized } \\
\text { Coefficients(B) }\end{array}$ & $\begin{array}{c}\text { Standardized } \\
\text { Coefficients (Beta) }\end{array}$ & $\mathrm{F}$ & $\mathrm{t}$ & Sig. \\
\hline Model Summary & .891 & .873 & & & 49.020 & & .000 \\
\hline $\begin{array}{l}\text { Model(F1) } \\
\text { (Constant) }\end{array}$ & & & $\begin{array}{l}-.172 \\
.753\end{array}$ & -.944 & & $\begin{array}{l}-7.001 \\
32.816\end{array}$ & $\begin{array}{l}.000^{\mathrm{a}} \\
.000\end{array}$ \\
\hline $\begin{array}{c}\text { Excluded } \\
\text { Variables }{ }^{b}(\mathrm{~F} 2)\end{array}$ & & & & & & -2.426 & .060 \\
\hline
\end{tabular}

a. Predictors in the Model: (Constant), F1

b. Dependent Variable: crste

The determination coefficient $\left(\mathrm{R}^{2}\right)$ of regression equation achieves 0.891 , and the adjusted $\mathrm{R}$ square is 0.873 , which means the fitting degree is high. The significance test of regression equation shows that there obviously exists linear relationship between dependent and independent variables, so that the linear model can be employed. The significance test of regression coefficients reveals that the corresponding independent variables are able to explain the change of dependent variable well. According to the standardized regression coefficient, the standardized regression equation was obtained eventually:

$$
\mathrm{Y}_{\text {crste }}=-0.944 \mathrm{~F} 1
$$

The following equation can be written combining with equations (5) and (6)

$\mathrm{Y}_{\text {crste }}=-0.37 \mathrm{FD}+0.11 \mathrm{BCI}-0.269 \mathrm{PD}+0.39 \mathrm{RND}$

With the same method, ' $F_{1}$ ' and ' $F_{2}$ ' were regressed with ' $\mathrm{Y}_{\text {scale }}$ ' and equation as follows can be obtained:

$$
\mathrm{Y}_{\text {scale }}=-0.913 \mathrm{~F} 1-0.375 \mathrm{~F} 2
$$

Combining with equations (5) and (6), the following equation was attained:

$\mathrm{Y}_{\text {scale }}=-0.281 \mathrm{FD}-0.127 \mathrm{BCI}-0.438 \mathrm{PD}+0.393 \mathrm{RND}(10)$

The quantified regression equation can not be obtained when ' $F_{1}$ ' and ' $F_{2}$ ' were regressed with ' $Y_{\text {vrste', which }}$ reveals that there has little linear relationship between urban form and the pure technical efficiency of urban resources.

The contribution degree of urban form indices to the change of urban resources efficiency can be measured by the equations above, from which it is clear that the influence of fractal dimension (FD) on urban resources efficiency is negative; while urban compactness ratio (BCI) and urban resources efficiency are not correlated directly; PD have negative impact on urban resources efficiency; road network density shows positive influence on urban resources efficiency.

As to the respective influence degrees, the order of influencing level of 'FD', 'PD' and 'RND' on the comprehensive efficiency of urban resources are: 'road network density' > 'FD'> 'PD', indicating that 'RND' have the most significant impact on urban resources efficiency; higher traffic level is beneficial for the optimal allocation and circulation of various urban resources, which would improve the efficient utilization of resources so that the waste could be avoided. The order of impact levels of urban form on urban resources scale efficiency are: 'PD'> 'RND' > 'FD', which reveals that 'PD' influences reversely urban resources scale efficiency most; increasing the investment of resources will gain no more returns in the area with higher PD,

\section{V.DISCUSSION}

From the above conclusions drawn from this study case, it is obvious that in Shanghai city urban resources efficiency is closely linked with urban form and different characteristics of urban form could impact the level of urban resources efficiency. The combination of urban form indices and urban resources efficiency is favourable for monitoring and evaluating urban expansion, as well as the changes of urban resources efficiency it induces scientifically and quantitatively, which can provide scientific basis for the economic and high efficient utilization of urban resources, as well as for the sustainable development of city.

\section{ACKNOWLEDGEMENTS}

The research work was supported by Doctoral Scientific Research Foundation of Shandong Jianzhu University under Grant No. XNBS1303.

\section{REFERENCES}

[1] Xinsheng Wang. (2005). "Study on methods for spatial analysis and their application in urban spatial form." Dissertation, Institute of Geographic Sciences and Natural Resources Research, CAS, Beijing..

[2] Batty, M., Longley, P. A. (1988). "The morphology of urban land use." Environment and Planning B: Planning and Design, 15(4), 461 488 .

[3] Wenhui Kuang, Shuwen Zhang, Zhang Yangzhen et al,. (2005). "Analysis of urban land utilization spatial expansion mechanism in Changchun city since 1990." Acta Geographica Sinica, 60(5), 841-850.

[4] Baoxing Qiu. (2006). "Compactness and diversity: Core of sustainable development of China.” City Planning Review, 30 (11), 18-21.

[5] Brian Marker. (2005). "Foundation of the sustainable compact city. " GBER., 4(3), 19-23.

[6] Michael Batty (2001). "Exploring isovist fields:space and shape in architectural and urban morphology". Environment and Planning B: Planning and Design,(28):123-150.

[7] Hillier, B. (1996). Space is the machine: A configurational theory of architecture. Cambridge University Press, New York.

[8] Dongfeng Zhu. (2007). Topological analysis on urban spatial development-A case study of Suzhou. Southeast university press, Nanjing.

[9] Jiang Li. (2005). "Fractal dimension of urban spatial morphology and its application." Engineering Journal of Wuhan University, 38(3), 99-103.

[10] Charnes, A., Cooper, W. W., Rhodes, E. (1978). "Measuring the efficiency of decision making units." European Journal of Operational Research, 2, 429-444. 